\title{
CORRIGENDUM
}

\section{Association between diet quality measured by the Healthy Food Intake Index and later risk of gestational diabetes - a secondary analysis of the RADIEL trial}

J Meinilä, A Valkama, SB Koivusalo, K Rönö, H Kautiainen, J Lindström, B Stach-Lempinen, JG Eriksson and M Erkkola

European Journal of Clinical Nutrition (2017) 71, 913; doi:10.1038/ejcn.2017.66

Correction to: European Journal of Clinical Nutrition (2017) 71, 555-557; doi:10.1038/ejcn.2016.275; published online 1 February 2017

Since the publication of this paper, the authors have noticed an error in the first author's name and an error in Table 2.
J Meinila should have been listed as J Meinilä.

The HFIl scores in Table 2 are in the wrong order; text 'highest' should be in place of text 'lowest' and vice versa for 'lowest'.

The authors apologise for any inconvenience caused.

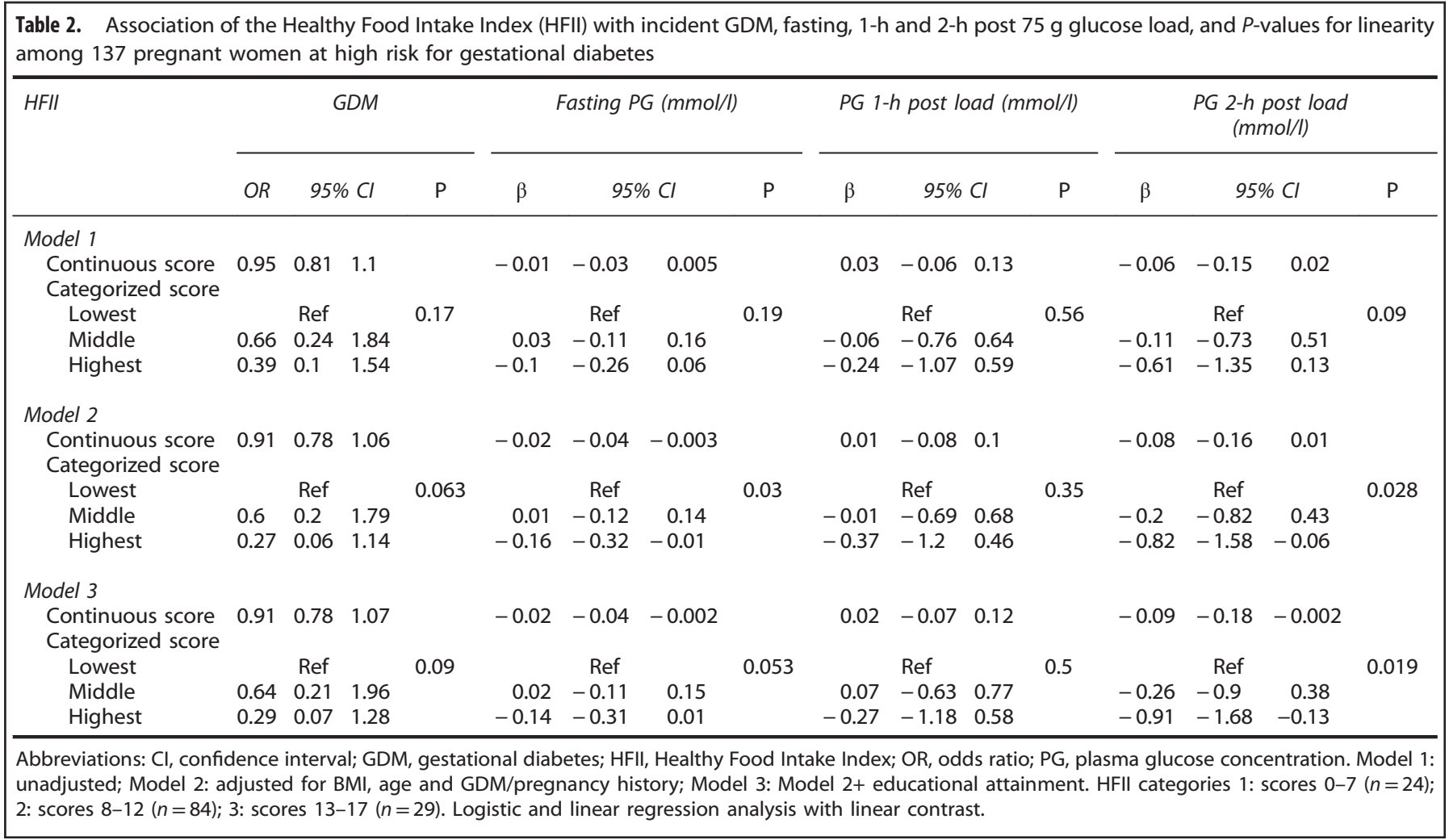

